Global Journal of Business and Social Science Review

Journal homepage: http://gatrenterprise.com/GATRJournals/index.html

\title{
Medical Tourism Development in Dubai: Managing Challenges and Opportunities
}

\author{
Anita Medhekar ${ }^{1 *}$ and Farooq Haq $^{2}$ \\ ${ }^{1}$ Central Queensland University, Rockhampton, QLD, 4701 Australia \\ ${ }^{2}$ Candian University Dubai, Dubai, PO Box 117781, UAE
}

\begin{abstract}
Objective - International medical travel is one of the fastest growing and lucrative segments of the tourism industry of this century. In the past, affluent people from Middle Eastern countries travelled abroad to the UK or USA for medical surgery and not wealthy citizens from developed countries are seeking affordable, accessible, world class quality of healthcare with modern medical technology, no waiting lists and combining it with a holiday. Dubai has established itself as a destination that can offer all this to foreign medical travellers.

Methodology/Technique - This paper is exploratory in nature and provides a conceptual study to investigate the expansion, challenges and economic opportunities for developing, promoting and managing Dubai as a medical tourism destination, which is a unique contribution to the theory of medical tourism management.

Findings - The study indicated several interesting findings regarding challenges such as highly dependence of UAE on foreign human resources, providing safety to migrant workers, implementing integrated medical tourism policy, global health insurance transferability, establishing legal and regulatory issues and others.

Novelty - This paper has presented ground breaking findings indicating the issues faced by the Dubai Government regarding the growth and sustainability of medical tourism. The lack of direct access to the Dubai Government and medical tourists is a limitation of this study
\end{abstract}

Type of Paper: Review

Keywords: Dubai; Medical Travel; Tourism; Development; Healthcare Management.

JEL Classification: I12, I19, Z32.

\section{Introduction}

Medical travel also known as medical tourism, treatment abroad, or cross border trade in healthcare is a market driven phenomenon. Medical tourism development and promotion as an export led growth strategy has been adopted by many developing Asian economies such as Thailand, India and Malaysia. Thus, global trade in healthcare services is now experiencing an exponential growth since 2010. Medical tourism is defined as an economic activity that entails trade in services medicine and tourism sectors, and people travel abroad with the

\footnotetext{
* Paper Info: Revised: September 17, 2016

Accepted: October 20, 2016

* Corresponding author:

E-mail: a.medhekar@cqu.edu.au

Affiliation: School of Business \& Law, Central Queensland University, Australia
} 
ISSN 2289-8506 @ 2016 Global Academy of Training \& Research (GATR) Enterprise. All rights reserved. 
aim of improving one's health (Bookman and Bookman, 2007). Medical travellers demand various types of superspecialties of treatment ranging from cardiac, cancer, cosmetic, dental, IVF-reproductive, orthopaedic, organ and tissue transplant to bariatric surgery. Foreign patients are seeking value for money when they travel abroad for specialists' surgery (Deloitte, 2008; Turner, 2011). Medical travel is "shaped by the complex interactions of myriad medical, economic social and political forces" (Horowitz and Rosensweig, 2007, p. 24) specific to that country.

Since the economic crisis of 2008, many industrial countries resorted to diversifying their economies and found tourism as the most relevant and convenient option. Even manufacturing and production oriented nations like the Japanese and Chinese converted their resources to enhance their tourism potential. Interestingly, the tourism industry inherently offers a further diversification of products and services. Following this trend, UAE in general and Dubai in particular, decided to shift the economy towards tourism with an innovative investment focusing on medical tourism. Dubai is progressing towards becoming a popular international destination and a regional hub for medical travel or cross border medical tourism due to its low cost, no waiting period, state-ofthe-art medical technology, and multi-lingual overseas educated human resources. All these attributes enable Dubai to claim high quality of Joint Commission International (JCI) accredited services in Dubai Healthcare City (DHCC) being in the trade free-zone (Ballentyne, 2015; JCI, 2016).

According to DHA, in 2015, in Dubai, 26 public and private hospitals treated 630,831 medical tourists, of which 293,359 (46\%) were foreign patients who travelled from abroad. Out of these foreign patients (43\%) were from Asian countries, European (15\%), African (7\%), American (5\%) and GCC (29\%) of those came from Asian countries. The main aim is to attract in-bound medical tourists and to gradually stop the out-bound medical travel of the UAE nationals. Dubai Health Authority (DHA), along with the governments' support is also trying to develop Dubai as a 'Global Destination for Medical Tourism'. This project was launched on 10th April 2016 by his Highness the Crown Prince and Chairman of the Executive Council of Dubai. DHA aims to attract 500,000 medical tourists by 2020 (Khaleej Times, 2016; Gulf News-Health, 2016).

Therefore, in strategic partnership with the Department of Tourism, Commerce and Marketing (DTCM), Directorate of Residency and Foreigners Affairs (RFA), Emirates Airlines (EA), private sector related businesses and twenty six public and private hospitals, Dubai Healthcare Experience Program (DHEP) has launched a comprehensive package of specialist medicals services for foreign patients. Further, potential medical tourists can search the information on a world's first electronic medical tourism portal, which provides comprehensive information about the Patient Protection Plan and Patient Bill of Rights. Medical travellers can purchase medical service package for the required treatment from medical facilities, apply for a medical visa, book Emirates tickets, hotel accommodation and local transport and plan their medical travel overseas on a single portal, along with medical insurance to cover for liability due to post-operative medical complications and malpractice, which is valid for one month from the day of surgery (Gulf News-Health, 2016). In light of the above discussion, this paper studies the management of the challenges and opportunities faced by medical tourism in Dubai, which is a global, cosmopolitan and educational and cultural heart of UAE.

\section{Background on Dubai}

\subsection{Government Healthcare Spending}

The main economy of UAE is oil, natural gas, trade, service sector, banking, finance, shipping, luxury real-estate and tourism. The government spends $70 \%$ on healthcare, as locals have developed a serious lifestyle related problems such as obesity, cardiac and diabetes. The cost of health insurance is low for expatriates which relates to work and traffic accidents. Overall total health cost in UAE is 50\% chapter than in the USA and UK. For sustainable tourism development planning is essential to achieve socio-economic goals (Steiner, 2010) by diversifying the economy. The government has developed and promoted Dubai as a healthcare city since 2002, which provides business friendly environment amongst the Middle Eastern countries. The development of DHCC 
has been driven by demand for healthcare by local ageing population, expatriate workforce and the foreign medical tourists.

\subsection{Service Sector}

Dubai's Smart City economic strategy is to create a knowledge driven economy by diversifying and encouraging investment, innovation and entrepreneurship driven by non-oil sectors. The key drivers of the UAE economy are trade, shopping, logistics, real estate, regional services, Islamic finance hub, and tourism and now trade in healthcare services /medical tourism. Therefore, development in local transport facilities, hospitals and museums and indoor sports and tourists attractions is essential to attract tourists from all over the world. The Government of Dubai has also played a key role in infrastructure development and promoting Dubai to the world, the travel and tourism sector will register an annual growth rate of $4.1 \%$ and create 245,000 jobs by 2023 (Alhosani and Zaidan, 2014).

\section{Literature Review}

Globalisation, internet, innovative medical technology and international trade, has led to the development and growth of trade and investment in healthcare services or medical tourism. Health tourism has two segments: wellness and medical. Medical travel is influenced by socio-economic, cultural and political factors which determined the decision to choose an overseas hospital, country, based on costs, quality, waiting time, privacy and confidentiality, availability of treatment, specialists expertise and patient safety (Turner, 2011; Connell, 2013; Medhekar and Ali, 2012; Medhekar, Wong, and Hall, 2014).

\subsection{Medical Tourism}

Medical tourism is a subset of health tourism. There are three types of medical tourists: intra-bound, in-bound and out-bound (Deloitte, 2008). There are various push factors that drive people to travel abroad for surgery, such as; long waiting list, high health and insurance costs, non-availability of medical surgery due to regulation, shortage of specialist medical staff, and ethical concerns. Whereas pull factors are affordable cost, no waiting list, uninsured and underinsured, JCI accreditation, English speaking and overseas educated surgeons, privacy and confidentiality, post-surgery care, state-of-the-art medical technology, language and cultural familiarity and being popular transit, sightseeing and shopping destination (Bookman and Bookman, 2007; Turner, 2011; Connell, 2013; Medhekar, et al., 2014).

Globalisation, information technologies and innovation in the global healthcare provision, have opened up entrepreneurial opportunities in providing medical treatment to foreign patients, by private hospitals as a strategy for economic development and diversification. Internet is a key driver for the growth of medical tourism by providing medical and healthcare information to the potential medical tourists (Lunt, Hardy, and Mannion, 2010).

- Affordable cost of surgery: Cost of elective and non-emergency surgery and health insurance costs can be very high and unaffordable in developed countries if one is uninsured and underinsured (Horowitz and Rosensweig, 2007; Hopkins et al., 2007; Turner, 2011; Connell, 2013). Patients search for information related to hospital, surgeon, quality, and country online. Therefore, patients travel abroad from developing countries and affluent class from developing countries for medical surgery to Asian destinations (Deloitte, 2008; Turner, 2011; Medhekar and Ali, 2012).

- International accredited quality of care: JCI has accredited highest number of 144 hospitals, clinics and diagnostic centers across UAE with 79 in Dubai, the second being the Kingdom of Saudi Arabia in the world (JCI, 2016). Quality of Accreditation becomes an important factor to choose a hospital by foreign patients, as there is a less perceived risk of medication and clinical errors, patient safety and infections after surgery. 
- No waiting list: Due to availability of medical procedures and no waiting time for surgery in Dubai, from initial consultation with the doctor to the specialist until surgery for cardiac or knee/hip surgery, (Hopkins et al., 2010; Johnston, Crooks, and Snyder, 2012; Connell, 2013; Medhekar at el, 2014), patients travel overseas for affordable quality of surgery to improve their health and quality of life.

- Destination and Hospital Attractiveness: Dubai in UAE has all the attractive features that an international tourists need in terms of desert sun in the winter time, sand, sea, shopping, skiing, safari, and sightseeing along with being centers of trade, commerce, luxury real estate investment and global financial services (Bagaeen, 2007; Balakrishnan, 2008; Inhorn, 2016) and familiarity with culture, religion, food and language (Medhekar and Haq, 2015). Similarly with the development of the Dubai HealthCare City (DHCC) in 2002 with nearly 120 healthcare facilities, the numbers of foreign patients visiting DHCC have increased by $15 \%$ each year (Ballentyne, 2015; Dominic, 2016) and government is also actively promoting Dubai as a global medical tourism hub of the Middle East.

\subsection{Health Tourism Development in Dubai}

According to Dubai Health Authority (DHA), in the first half of 2015, one billion Dirham in foreign exchange was earned from 260,000 (40\%) in-bound medical tourists who visited Dubai for surgery. It is expected that the growth of inbound medical tourism to be $12-15 \%$ per year, that is a projected growth of 500,000 medical tourists by 2020 . The most popular treatments are: cosmetic, plastic surgery, dental, infertility, eyes, dental, sports medicine, reconstructive surgery, bariatric, and orthopaedic (Ballentyne, 2008). Dubai is also developing wellness along with medical travel and medical tourism facilitator is also growing, for example Salamatak Healthcare Management, who bring in-bound patients and provide a cost effective package which includes travel, local transport and transfers, accommodation and medical services and translation services. The total foreign exchange revenue earned by UAE through medical tourism in 2012 was Dirham 652 million, with 107,000 inbound medical travellers to UAE, with the number of foreign patients expected to rise by 170,000 in 2016, generating a total revenue of dirham 1.1 billion (Kannan, 2014). In the first half of 2016 nearly 260,000 foreign patients travelled to DHCC due to cost, convenience of travel and cultural preference (Dominic, 2016).

\section{Healthcare Policy Dubai}

Government of UAE provides comprehensive healthcare to all its citizens, irrespective of their ability to pay, based on the privileges awarded to UAE citizens or 'emiratization' (Inhorn, 2016). Ministry of Health and DHCC are responsible for health facilities, accreditation of hospitals and medical staff and regulation. This has been made possible by supporting economic diversification by collaborating with leading medical centers, corporations and medical schools from the USA, in addition to building healthcare infrastructure, hospitals, clinics, and at the same time develop and invest in local workforce. With the issues of ageing population and less active youth, citizens of the UAE are faced with chronic, lifestyle health problems similar to those faced by the developed countries. The UAE is also under pressure to meet the healthcare demand of a large number of foreign migrant workforce.

The UAE health system is provided by the public as well as private providers. Public health hospitals are managed and regulated by five departments of the government. Whereas the private healthcare providers like $\mathrm{Al}$ Noor Hospital, New Medical Centre, Dubai healthcare City provide super-specialty of healthcare services. UAE Vision-2021 is to ensure and provide universal access to world class quality healthcare services which is easily accessible, available and affordable. Vision 2021 states that "the UAE [will]... invest continuously to build worldclass healthcare infrastructure, expertise and services in order to fulfill citizens' growing needs and expectations" (The UAE Healthcare Sector, 2014). 


\subsection{Opportunities}

Analyzing from the economic impact perspective, development of medical tourism will provide employment opportunities in medical, allied healthcare services and tourism sector which is specially designed and developed for medical patients/ travellers with illness, and also proving an important source of foreign exchange for the country (Medhekar et al., 2014; Medhekar and Haq, 2015). Diversifying into medical tourism, will also improve local public infrastructure, such as health, wheelchair access to tourism places and transport facilities which also benefits the locals. Further, empirical research shows that repeat visits from the medical travelers must be ensured by providing affordable quality of medical product and medical service pre- and post-surgery and trust in a customer-provider relationship (Han and Hyun, 2015). The elements indicating the opportunities extracted from the UAE Healthcare policy are detailed below:

a) The Dubai government has adopted a development strategy by providing pro-business environment through public-private ties via informal channels to formulate and implement the vision of the rulers (Hvidt, 2007). b) Dubai has attracted international private intellectual and financial capital investment from all over the world to support the business development to stabilise and modernize the economy. c) Dubai is a global city and provides local cultural experience to international tourists (Henderson, 2014).

b) Medical tourism development also provided opportunities to develop not only Dubai Health Care Medicity but also 'medical hotels' similar to nursing homes, catering to outpatients (Han and Hyun, 2014). Hence it is equipped to offer to medical patients as the travelers' need under one roof, for pre and post care, accommodation with facilities of healthcare, wheelchair access, rooms catering to patients, clinic, pharmacy and first-aid. The competitive edge Dubai has in healthcare is based on all above mentioned healthcare services delivered with all 3 to 5 star hotel style ambiance and services.

c) Dubai proudly presents state-of-the-art tourism infrastructure, high tech medical super-specialties and technology to provide treatment to locals, foreigners and expatriates in cardiac, cosmetic, dental, orthopaedic, organ and tissue transplant, bariatric, and IVF-reproductive clinics (Inhorn, 2016).

d) Dubai government has also introduced 3 months medical tourists' visa to encourage foreign patients to seek treatment in the UAE. Short-stay Visa category for medical doctors is also introduced to make it easy for the hospitals to invite visiting medical specialists from overseas. The multi-specialty Cleveland Clinic in Dubai collaborates with world class medical expertise resulting in an increase in in-bound medical travel (WHO, 2015).

e) The government in 2013 had to transfer several UAE nationals to developed countries for surgeries not available at home, such as cardiology, oncology and neurosurgery at a cost of $\$ 44,000$ US Dollars per patient (Dominic, 2016). This out-bound medical travel cost can be saved if these treatments are available in UAE with the development DHCC.

f) The challenge is that due to global competition, it is essential that medical tourists make repeated visits to the clinics in Dubai. Familiarity with local culture usually attracts diaspora and cross-border medical tourists and those expatriates living for many years in UAE feel comfortable with the healthcare services. Finally, Dubai should reap the benefits of its destination attractiveness, which it has to offer given the competitive global environment to attract foreign tourists in terms of personal safety, quality, transport and overall value for money. UAE healthcare investment strategy is a success story providing world class health-care infrastructure and technology to its citizens and to global medical tourists.

\subsection{Challenges}

The UAE government provides equal access to healthcare to all its citizens, but also faces many global challenges. Firstly, there is a conflict between meeting objectives of being state-sponsored 'cosmopolitan' global city for the foreigners and also the 'emiratization' as only 1 million constitutes UAE nationals, from a total population of 9 
million (Inhorn, 2016). Secondly, since September 11, the Arab spring and Middle Eastern wars, in bound tourism flows across the Middle East has dropped. However, comparatively UAE has shown political stability and successful tourism development strategies for its sustainability, where international patient mobility in a global and cosmopolitan Dubai is on the rise (Lunt and Mannion, 2014; Inhorn, 2016). Analyzing both these factors, this paper accepts it as a challenge. However, this foreign and Middle-Eastern situation could be seen as an opportunity and a challenge to attract medical tourists from the region.

a) UAE largely depends on foreign human resources (medical professionals, nurses, para medical staff and allied healthcare workers). b) Improving migrant workers safety and living conditions- professionals as well as poor working class construction workers. c) Global Public-Private-Partnerships are required to be established between medical hospitals, medical schools, accrediting agencies and Medi-tour facilitators. d) An integrated medical tourism policy with DHA, DTCM, RFA, EA, DHEP and medical schools and ministry responsible for local safety. e) Possibility of global health insurance transferability. f) Establishing legal and regulatory issues to protect the hospital, surgeon and the foreign patient. g) Creating investment friendly environment to attract foreign direct investment (FDI) in health infrastructure, nursing homes and medical travel hotels. h) Avoiding bureaucratic delays required for FDI in health and medical facilities. i) Being sensitive to protecting and promoting local environment, social, cultural issues through tourism. j) National and international accreditation (JCI) of the medical hospitals and Medi-tour operators for quality control k) Building trust and confidence in the quality of medical services and in local and expatriate medical professionals, nursing and other non-medical staff, who should have patient-friendly hospitality and patient-focused health care. 1) UAE-has to face competition from other popular medical tourism destinations providing world class medical tourism.

\section{Medical Tourism Policy Recommendations}

Dubai can build on its global business, corporate brand identity (Bagaeen, 2007; Balakrishnan, 2008) and JCI international accreditation, by adopting the export of healthcare services, and promote Dubai as a 'Medical Tourism Hub' and also provide Islamic hospitality (Stephenson, 2014; Medhekar and Haq, 2015).

To become a 'Global Healthcare Medi-City' Dubai should implement 14Ps of medical tourism healthcare patient-marketing-mix (Medhekar et al., 2014): i) Products- (medical-tangible and intangible) healthcare products; ii) Price- of medical travel and treatment to be competitive and affordable; iii) Place- of medical treatment- to develop JCI accredited medical faculties in all major cities of UAE; iv) Promotion- of all super speciality of healthcare services available in UAE, which are JCI accredited to foreigners; v) Patient and Personalattract patients from all over the world, and quality of medical and non-medical staff; iv) Physical Proof - of world-class medical facilities, with foreign trained doctors, international accreditation, medical equipment; vii) Process or Procedure - related to information flow and process that a medical tourist is involved in various stages of interacting with the hospital and medical travel facilitator; viii), Public-Private Partnerships - (PPP) with world class medical schools, hospitals and pharmaceuticals, health and tourism industry for providing, and promoting world quality of global healthcare. ix) Personalization of patient healthcare - which is tailor-made for each patient as per their health problems and requirements; $x$ ) Publications - of health and medical information or physical evidence of the corporate or brand logos, brochures, stationary and advertisement; xi) Patient Packaging - where a medical tourist pays a combined price for various services packed together from start to end of the medical travel for consumers convenience; xii) Patient Education - where the websites of the hospitals provide information regarding the health care services, management of the disease; xiii) Patient Privacy - and confidentiality of patients and medical records xiv) Patient Health, Medical and Cultural Sensitivities - for example, provision of interpreting services, prayer room, food /dietary requirements, is essential for the overall sustainability of medical tourism business.

The hospital and its specializations need to be positioned, branded and marketed as a niche for medical treatment in Dubai. Government policy initiatives should aim for sustainable development, promotion, marketing, and packaging of 'Dubai Healthcare City' to Muslim patients to attract inbound medical tourists 
(Malaysia being in competition). The Dubai Government needs to participate in Global health and spa summit and trade fairs to raise awareness of Dubai Healthcare City and specialist treatment.

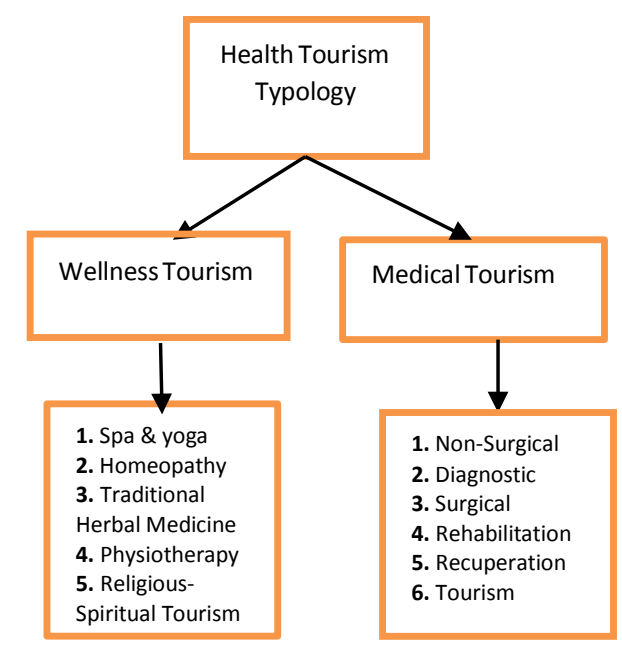

Figure 1: Health Tourism Typology for Dubai Source: (Adapted from Medhekar at al., 2014)

Figure 1 indicates that the Health Tourism Typology in the case of Dubai, UAE, embedded with wellness tourism, since only quality of medical tourism is insufficient to gain competitive advantage in this dynamic market. Whereas, the wellness tourism can be further customized and uniquely designed to attract and retain normal tourists to Dubai visiting for business, shopping and sightseeing experience.

\section{Conclusions}

This paper has presented ground breaking findings indicating the issues faced by the Dubai Government regarding the growth and sustainability of medical tourism. The main contribution of this exploratory paper has been the study of the medical tourism development and management of challenges and opportunities in Dubai. Another outstanding contribution of this study to tourism theory is the application of the 14 Ps of medical tourism healthcare patient-marketing-mix, applied for healthcare management in Dubai which can be replicated for medical tourism in different countries.

This study indicates that medical tourism in Dubai can be successful if the elements of the wellness tourism along with medical could be considered to develop and manage as a medical tourism destination. Moreover, wellness tourism could contain traditional herbal medicine and other wellness therapies as supplements for pre or post surgeries for recuperation. These herbal drugs could be collected from various Arab countries. Another differentiating agent for UAE medical tourism could be to arrange religious classes or teachings based on multireligious books and people. Since most patients are vulnerable after surgery and become more religiously sensitive, Dubai Medi-City could arrange to have religious people from various religions to attend to these patients, and their escorts, to deliver religious prayers to calm their senses and offer spiritual counselling support to improve their health and wellbeing, after going through surgery abroad.

The main strength of UAE government is in its culture to adopt and embrace global trends and changes to be a global player in trade, finance, health, tourism and travel. The development of the non-oil sector and service sector is further influenced by the geography, socio-cultural, economic and political factors. During the global financial crisis Dubai tourism declined from the high-end of foreign tourists. Dubai is similar to Singapore in terms of providing unique, traditional, cultural and authentic blend of tourism product and services. The vision of the ruler of Dubai to diversify the economy with political and economic stability is the driving force to establish Dubai as a Global Healthcare Hub. 
The development of medical tourism puts Dubai on the map not just for its trade in traditional goods and services, but also adopting globalization and diversifying its economy in developing global medical tourism destination. This is all possible with the development and growth of DHCC, with super-specialties of world class medical facilities by the private sector, attracting and retaining word class foreign medical professionals. Hence, the increased international competitiveness in healthcare delivery, improves overall foreign medical tourists experience in healthcare. Medical tourists are making informed personal healthcare decisions to get the best product with a memorable holiday. Medical tourism specialised treatment, hospital and destinations to be positioned, branded \& marketed as a niche for medical treatment in Dubai. Government policy initiatives for the sustainable development, promotion, marketing, and packaging of 'Dubai Healthcare City' to Muslim patients to attract inbound medical tourists (Malaysia being in competition). The Dubai Government needs to organise and participate in World MT congress, Global health and spa summit and trade fairs to raise awareness of Dubai Healthcare City and specialist treatment.

Dubai is similar to Singapore in terms of providing unique, traditional, cultural and authentic blend of tourism product and services. The vision of the ruler of Dubai to diversify the economy with political and economic stability is the driving force behind medical tourism planning to establish Dubai as a Global Healthcare Hub in the Middle East. This stability is necessary to attract private sector and foreign investment in start-up firms, infrastructure and local human capital to diversify the economy in developing world class global medical tourism destination. Globalization, digitization, communication technologies and logistics have made healthcare delivery innovative for a global patient, where the world is soon becoming our hospital. The limitation of this study is that it is an exploratory paper and therefore a lack of direct access to the Dubai Government Health Authority and key stake holders from the supply side and actual medical tourists to Dubai from the demand side is a major limitation of this study. A future empirical study could be conducted in Dubai from the supply side to get insights into management and marketing issues related to medical tourism; and the demand side perspective of medical tourists after going through surgery in Dubai.

\section{References}

Alhosani, N. \& Zaidan, E. (2014). Shopping Tourism and Destination Development: Dubai as a Case Study. The Arab World Geographer, 17(1), 66-81.

Bagaeen, S. (2007). Brand Dubai: The instant city; or the instantly recognisezable city. International Planning Studies, 12(2), 173-197.

Balakrishnan, M. S. (2008). Dubai- A star in the East. Journal of Place Management and Development, 1(1), 62-91.

Ballentyne, B. (2015). Huge opportunity for health tourism. Middle East Economic Digest, 59(6), 1-3.

Bookman, M. Z., \& Bookman K. R. (2007). Medical tourism in developing countries. New York: Palgrave MacMillan.

Connell, J. (2013). Contemporary medical tourism: conceptualisation, culture and commodification. Tourism Management, $34,1-13$.

Deloitte (2008). Medical Tourism: Consumers in Search of Value, Deloitte Centre for Health Solutions, Washington, D.C. Dominic. D. (2016). Medical tourism holds promising potential for UAE. Middle East Economic Digest, 60(2), 1-5.

Gulf News-Health (2016-7-13). Retrieved from http://gulfnews.com/news/uae/health/dubai-launches-world-s-first-medicaltourism-portal-1.1707862.

Han, H., \& Hyun, S. S. (2014). Medical Hotel in the Growth of Global Medical Tourism. Journal of Travel \& Tourism Marketing, 31(3), 366-380.

Han, H., \&. Hyun, S. S. (2015). Customer retention in the medical tourism industry: Impact of quality satisfaction, trust, and price reasonableness. Tourism Management, 45, 20-29.

Henderson, J. C. (2014). Global Gulf Cities and Tourism: A Review of Abu Dhabi, Doha and Dubai. Tourism Recreation Research, 39(1), 107-114.

Horowitz, M. D., \& Rosensweig, J. A. (2007). Medical Tourism-Health Care in the Global Economy. The Physician Executive, 33(6), 24-31.

Hopkins, L., Labonte, R., Runnels, V., \& Packer, C. (2010). Medical tourism today: What is the state of existing knowledge? Journal of Public Health Policy, 31(2), 185-198. 
Hvidt, M. (2007). Public-private ties and their contribution to development: The case of Dubai. Middle Eastern Studies, 43(4), 557-577.

Inhorn, M.C. (2016). Cosmopolitan conceptions in global Dubai? The Emiratization of IVF and its Consequences. Reproductive Biomedicine Society, 2, 24-31.

JCI. (2016). Joint Commission International Accreditation Standards for Hospitals. Retrieved from http://www.jointcommissioninternational.org/about-jci/jci-accredited-or

Johnston, R., Crooks, V., \& Snyder, J. (2012). I didn't even know what I was looking for: A qualitative study of the decisionmaking processes of Canadian medical tourists. Globalisation and Health, 8(23), 2-12.

Kannan, P. (2014). Retrieved from The National, http://www.thenational.ae/uae/tourism/dubai-reveals-master-plan-for-500000-medical-tourists-a-year.

Khaleej Times Dubai (2016), Retrieved from http://www.khaleejtimes.com/nation/dubai/dubai-to-attract-500000-medicaltourists-by-2020.

Lunt, N., Hardey, M., \& Mannion, R. (2010). Nip, Tuck and Click: Medical Tourism and the Emergence of Web-Based Health Information. The Open Medical Informatics Journal, 4(1), 1-11.

Lunt, N., \& Mannion, R. (2014).Patient mobility in the global marketplace: a multidisciplinary perspective. International Journal of Health Policy Management, 2(4), 155-157.

Medhekar, A., \& Haq, F. (2015). Halal Branding of medical Tourism: case of Indian hospitals. In Hatem El-Gohary \& Riyad Eid (eds.), Emerging Research in Islamic Marketing and Tourism in the Global Economy, (Chapter 8, pp. 160-189), Penn, USA: IGI Global Publishing.

Medhekar, A., \& Ali, M. M. (2012). A Cross-Border Trade in Healthcare services: Bangladesh to India. The Business and Management Review, London, 2(1), 1-13.

Medhekar, A., Wong, H. Y., \& Hall, J. (2014). Innovation in Medical Tourism Services Marketing: A case of India. In A. Goyal (Ed.), Innovations in Services Marketing and Management: Strategies for Emerging Economies, (Chapter 3, pp.49-66), Penn, USA: IGI Global Publishing.

Steiner, C. (2010). From heritage to hyper-reality? Tourism destination development in the Middle East between Petra and the Palm. Journal of Tourism and Cultural Change, 8(4), 240-253, 2010.

Stephenson, M. L. (2014). Deciphering 'Islamic hospitality': Developments, Challenges and Opportunities. Tourism Management, 40, 155-164.

The UAE Healthcare Sector (2014), [Online]. Available at: http://usuaebusiness.org/content/uploads/2014/06/HealthcareReport.pdf.

Turner, L. (2011). Quality in health care and globalisation of health services: accreditation and regulatory oversight of medical tourism companies. Journal of Quality in Health Care, 23(1), 1-7.

WHO (2015). UAE Health Stategy. Retrieved from: http://www.who.int/countryfocus/cooperation_strategy/_en.pdf 